${ }^{1}$ Department of Restorative Dentistry, Faculty of Dentistry, Federal University of Minas Gerais (UFMG), Belo Horizonte, Minas Gerais, Brazil

${ }^{2}$ Department of Chemistry, Paulista State University (UNESP), Araraquara, São Paulo, Brazil
Corresponding author: Hugo Henriques Alvim, DDS, MS, PhD Professor, Department of Restorative Dentistry, Faculty of Dentistry, Federal University of Minas Gerais (UFMG), Av. Presidente Antônio Carlos 6627, Belo Horizonte, CEP 31270-901, MG, Brazil E-mail: hugoalvim@gmail.com, Tel: +55 31-3409-2440, Fax: +55 31-3409-2440

Received: July 29, 2020

Accepted: September 30, 2020

\section{Cytotoxicity and degree of conversion of methacrylate and silorane}

Virgínia Angélica Silva ${ }^{1}$ (iD, Sávio Morato de Lacerda Gontijo' ${ }^{1}$, Alexandre Gatti ${ }^{2}$ iD, Luiz Thadeu de Abreu Poletto $^{1}$ (iD, Hugo Henriques Alvim ${ }^{1, *}$ (iD

\begin{abstract}
Composites have been proven to have a cytotoxic effect on a variety of tissues and cells. Aim: The aim of this study was to analyse the degree of conversion of resins and its correlation with the cell viability in primary gingival fibroblasts. Methods: Resin-based silorane (Filtek P90) and conventional methacrylate resins (Filtek Z100, Filtek Z250 and Filtek Z350XT) were used to evaluate cell viability and the degree of conversion. The resins were light-cured by a LED for 20 and 40 seconds. The degree of conversion was analysed by Fourier transform infrared spectroscopy. Cellular metabolism was evaluated after 24 hours by the MTT assay $(n=6)$ using the storage solution of composite resin for either 24 hours or 12 days. Variance analysis (ANOVA) with a Bonferroni correction $(p<0.05)$ was performed to compare the groups. Results: The composite Filtek P90 showed a higher degree of conversion when polymerised for 40 or 20 seconds, while the composites Filtek Z100, Filtek Z250 and Filtek Z350XT showed similar degree of conversion. Only the Filtek Z100 resin was cytotoxic. Conclusion: We found no statistically significant correlation between cell viability and the degree of conversion.
\end{abstract}

Keywords: Composite resins. Cytotoxins. Fibroblasts. 


\section{Introduction}

Light-cured composite materials have been used as fillers in restorative dentistry for a number of years and are an established alternative to amalgam ${ }^{1}$. However, it has been demonstrated that composite restorative materials continue to release resin monomers and other components even after polymerisation. Degradation can lead to resin-based dental material components leaching into the oral environment and initiating adverse effects².

After polymerisation, unbound monomers and additives are extracted by solvents, e.g. saliva and/or digestive solvents, especially during the first 24 hours. Previous studies revealed a variety of potential cytotoxic and metabolic effects due to the leaching of these methacrylates from the restorations, such as teeth sensitivity, local immunological effects, chronic inflammatory reactions of human pulps, genotoxicity and apoptosis ${ }^{2-4}$.

By varying the composite compounds, the manufacturers can influence the physical and chemical properties to suit special requirements regarding handling, clinical acceptance and the toxicity of these materials. Due to the severe cytotoxicity of some traditional composites like methacrylate, industries are searching and developing new materials and new strategies. Materials based on modern chemistry (e.g. silorane, Ormocer) have been shown to be the most biocompatible ${ }^{5}$.

Resins containing the monomer Silorane (Filtek P90) are based on the replacement of the methacrylate monomers system for an epoxy ring-opening-silorane. The monomer silorane is obtained by the reaction between siloxane and oxirane and has shown to have a shrinkage percentage of only $0.99 \mathrm{vol} \% 3,6$ while methacrylate has been shown to have an average contraction of $2.33 \%$ vol over time ${ }^{7}$. The siloxane component brings a higher hydrophobicity to the material, while the oxirane component has a higher reactivity and a lower polymerisation shrinkage ${ }^{8}$. In addition, the degree of conversion of silorane-based resin has been shown to be greater than that of methacrylate-based resin compounds ${ }^{9}$.

Composites have been proven to have a cytotoxic effect on a variety of tissues and cells. Cell culture studies are frequently used to assess the cytotoxicity of resin-based materials and their component $s^{10}$. Among these cells include gingival fibroblasts that are closely related to restorative materials, especially in Class II restorations ${ }^{4}$.

The cytotoxicity of a composite is related both to its chemical composition and to the conversion percentage of its monomers. As it is known, a high conversion percentage is vital for good mechanical properties and biocompatibility 11,12. Low values of double bond conversion involve a large number of residual monomers trapped in the polymeric matrix, reducing its biocompatibility. However, the cytotoxicity presented by the Filtek Z350XT resin in gingival fibroblasts did not correlate with the degree of conversion ${ }^{13}$

There are few studies in the literature that have evaluated the relationship between cytotoxicity and the degree of conversion ${ }^{12,13}$. Thus, the present study aimed to evaluate the cytotoxic effect on primary gingival fibroblasts from different materials used 
in restorative dentistry and to analyse the degree of conversion of these materials and its possible correlation. The null hypothesis tested was that a lower degree of conversion of the resin would result in lower cytotoxicity in gingival fibroblasts.

\section{Materials and Methods}

\section{Materials and sample preparation}

The resin composites used in this study were obtained from 3M ESPE (Table 1).

Table 1. Resin composite used in this study with respective matrix and inorganic filler

\begin{tabular}{lcc}
\hline Products & Resin matrix & \% Inorganic filler \\
\hline Filtek P90 & Silorano & 76 \\
\hline Filtek Z350XT & Bis-GMA, Bis-EMA, UDMA, TEGDMA & 78,5 \\
\hline Filtek Z100 & Bis-GMA, TEGDMA & 71 \\
\hline Filtek Z250 & Bis-GMA, Bis-EMA, UDMA, TEGDMA & 60 \\
\hline
\end{tabular}

The specimens were fabricated in a glass matrix, (4 mm diameter $\times 2 \mathrm{~mm}$ height) under aseptic conditions. The moulds were placed on a glass plate, and the restorative materials were condensed into them from above. A mylar strip was applied to the surface. The specimens were divided into two groups which were light-cured from above for 20 or 40 seconds, with the curing tip placed $2 \mathrm{~mm}$ away from the material surface, simulating the distance between the composite and the pulp wall. A diode light source emitting blue light (Flash lite, DISCUS Dental, Culver City, USA) was used to cure the resin composites. Irradiation intensities (570-600 mW/ $\left.\mathrm{cm}^{2}\right)$ were monitored during the test by an external radiometer (MODEL 100 Curing Radiometer, Demetron/ Kerr, Danbury, CT, USA). Excess flash was trimmed away with a sterile scalpel, and the discs were removed by extrusion of the glass matrix and immediately stored in a dry and protected from the light environment.

\section{Cell culture}

Primary human gingival fibroblasts (HGFs) were purchased from American Type Culture Collection (ATCC; Manassas, VA, USA). The HGFs were cultivated in Dulbecco's Modified Eagle Medium (DMEM) with 10\% foetal bovine serum (FBS) and $0.1 \%$ antibiotic-antimycotic solution at $37^{\circ} \mathrm{C}$ and $5 \% \mathrm{CO}_{2}$.

\section{MTT assay}

The sterilised specimens by ethylene oxide, were placed in $1 \mathrm{~mL}$ of DMEM without FBS and incubated at $37^{\circ} \mathrm{C}$ in a $5 \% \mathrm{CO}_{2}$ air atmosphere for two periods: 24 hours or 12 days $(n=6)$. Fresh DMEM was used as the control group. Exponentially growing cells were seeded in 96-well plates at a density of $5.0 \times 10^{3}$ cells/well and were cultured for 24 hours. After this, the culture medium was replaced with $100 \mu \mathrm{L}$ of culture medium containing the material extracts of the resin-based restoratives and incubated for 24 hours. 
Cell viability was evaluated according to the reduction of tetrazolium salt to formazan crystals. Briefly, MTT solution $\left(10 \mu \mathrm{L} ; 5 \mathrm{mg} \cdot \mathrm{mL}^{-1}\right)$ plus $100 \mu \mathrm{L}$ of growth medium were added to each well, and then the plates were incubated at $37^{\circ} \mathrm{C}$ in a $5 \% \mathrm{CO}_{2}$ atmosphere for 4 hours. Sodium dodecyl sulphate (SDS; $100 \mu \mathrm{L}$ ) was added to dissolve the formazan, and the absorbance was measured at $570 \mathrm{~nm}$ by a spectrophotometer (Thermo Scientific Multiscan Spectrum, Vantaa, Finland) after 4 hours of incubation. Cell survival was calculated as the percentage of the dye accumulated in the untreated controls ${ }^{14}$.

\section{FTIR assay}

The degree of conversion (\%DC) was assessed by micro-attenuated total reflectance Fourier transform infrared spectrometry (micro-ATR FTIR). The FTIR spectrometer (Spectrum 2000 - Perkin Elmer, Boston, MA, USA) was operated under $4000-400 \mathrm{~cm}^{-1}$ range, $2 \mathrm{~cm}^{-1}$ resolution and 32 scans per sample. Three specimens of each material were prepared as described above and placed immediately in the sample holder of the device, and the spectra were recorded.

For the methacrylate resin-based composites (Filtek Z100, Filtek Z250 and Filtek Z350XT), the peak intensity ratio of aliphatic $C=C$ to aromatic $C=C\left(1638\right.$ and $1609 \mathrm{~cm}^{-1}$, respectively) was evaluated before and after irradiation to determine the percentage of unsaturated aliphatic $\mathrm{C}=\mathrm{C}$ bonds remaining ${ }^{9}$. The absorption of the aromatic $\mathrm{C}=\mathrm{C}$ stretching band remains constant during polymerisation and serves as an internal standard (Figure 1). Then, the DC of each methacrylate specimen was calculated according to Eq. (1).

$$
\frac{(\% \mathrm{C}=\mathrm{C})=(\text { aliphatic } \mathrm{C}=\mathrm{C} / \text { aromatic } \mathrm{C}=\mathrm{C}) \text { polymer }}{(\text { aliphatic } \mathrm{C}=\mathrm{C} / \text { aromatic } \mathrm{C}=\mathrm{C}) \text { monomer }}
$$

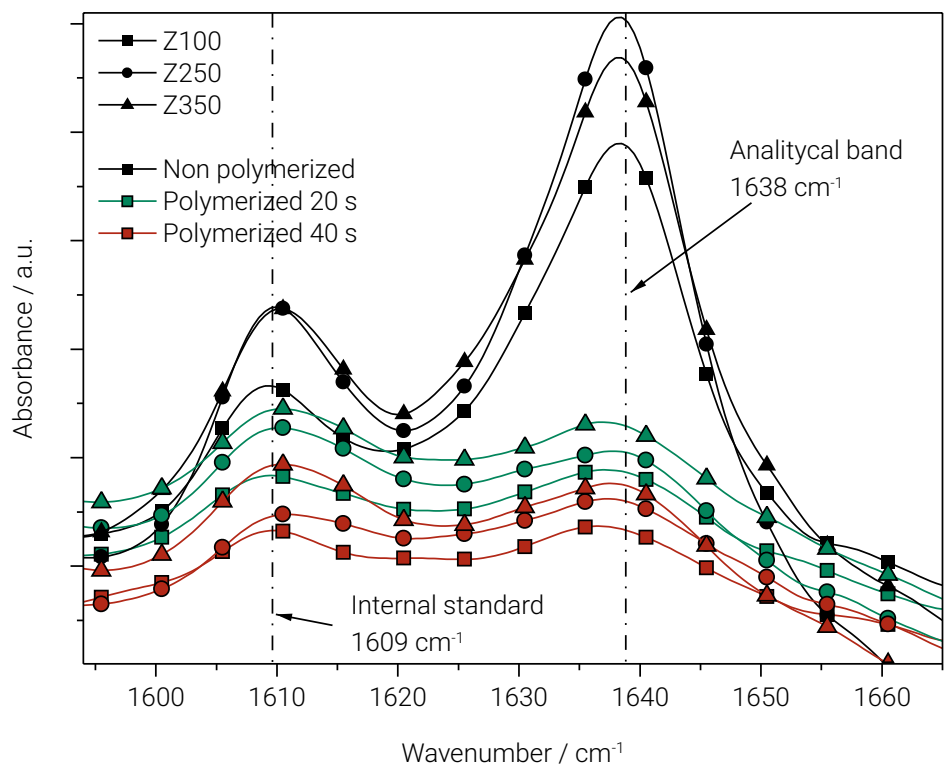

Figure 1. FTIR spectra exhibiting the reduction in the peak height at $1638 \mathrm{~cm}^{-1}$ associated with the saturation of aliphatic $\mathrm{C}=\mathrm{C}$ within the resin-based methacrylates $(\mathrm{Z100}, \mathrm{Z250}$ and Z350XT). Absorption of the aromatic $\mathrm{C}=\mathrm{C}$ stretching band $\left(1609 \mathrm{~cm}^{-1}\right)$ remains constant during polymerisation. 
The monomer of the silorane resin-based composites (Filtek P90) does not contain aliphatic $\mathrm{C}=\mathrm{C}$ groups $\left(1610 \mathrm{~cm}^{-1}\right)$, remaining constant during polymerisation. The mean \%DC of silorane specimens were identified through the FTIR spectra in $883 \mathrm{~cm}^{-1}$, which corresponded with the oxirane ring-opening regions (Figure 2). Then, the \%DC of silorane specimen was calculated according to Eq. (2).

$$
\frac{(\% \mathrm{C}-\mathrm{O}-\mathrm{C})=(\text { oxirane }(\mathrm{C}-\mathrm{O}-\mathrm{C}) \text { /aromatic } \mathrm{C}=\mathrm{C}) \text { polymer }}{\text { (oxirane }(\mathrm{C}-\mathrm{O}-\mathrm{C}) \text { /aromatic } \mathrm{C}=\mathrm{C}) \text { monomer }}
$$
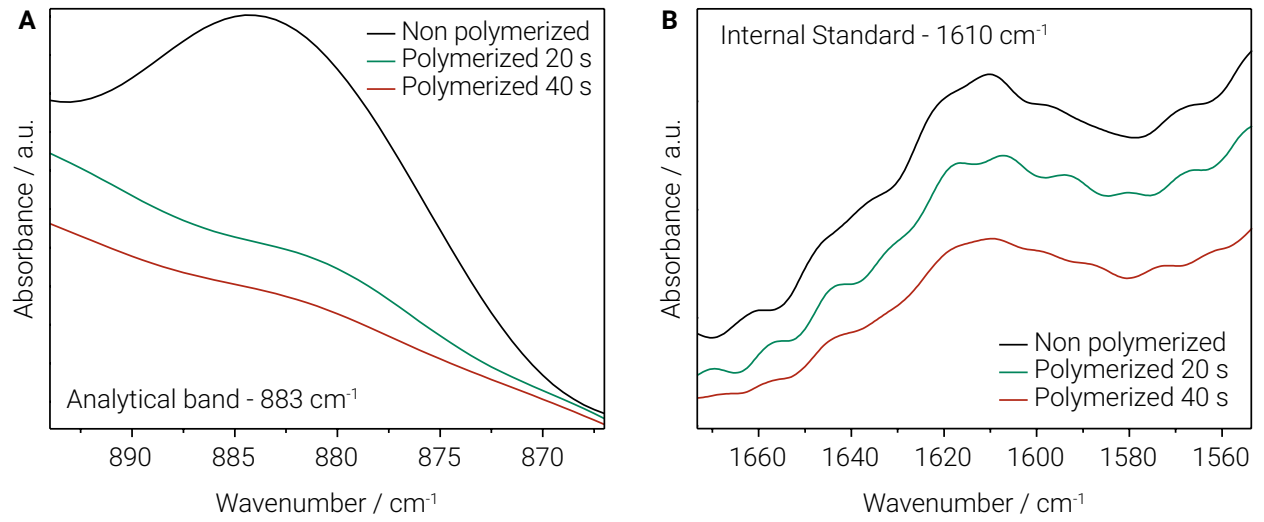

Figure 2. FTIR spectra exhibiting the $(A)$ reduction in peak height at $883 \mathrm{~cm}^{-1}$ associated with the saturation of the oxirane rings within the resin-based oxirane (Filtek P90); (B) absorption of the aromatic $\mathrm{C}=\mathrm{C}$ stretching band $\left(1610 \mathrm{~cm}^{-1}\right)$ remains constant during polymerisation.

\section{Statistical analysis}

Statistical analyses were performed using an analysis of variance (ANOVA) followed by the Bonferroni test. The level of significance was set at $p<0.05$.

\section{Results}

\section{The cell viability}

The mitochondrial reducing activity assessed with the MTT assay was inhibited only by Filtek Z100 (20 and 40 seconds) in both periods of pre-incubation ( 24 hours or 12 days). For all the resins evaluated, the variation of the polymerisation time did not affect the percentage of cell viability (Figure 3). 
A

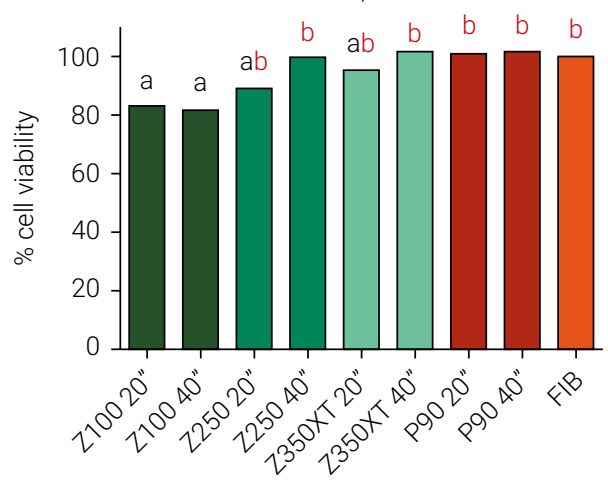

B

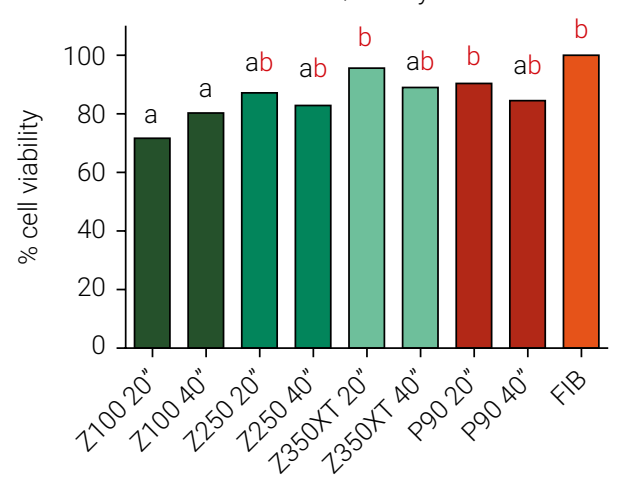

Figure 3. Percentage gingival fibroblast viability after incubation with composite extracts after (A) 24 hours or (B) 12 days. (FIB = fibroblasts; the same letters indicated similar groups).

\section{Degree of conversion}

Among the assessed resins, Filtek P90 showed the highest \%DC. Statistical comparisons showed a significant increase in the \%DC of Filtek Z100 and Filtek P90 when cured for 40s compared to cured for 20s. Filtek Z250 and Filtek Z350XT did not reveal significant differences between \%DC when cured for 20 or 40 seconds (Table 2). No correlation was found between the degree of conversion and cell viability.

Table 2. Degree of conversion (DC) of resin composites after irradiation by 20 or $40 \mathrm{~s}(\mathrm{n}=3)$. Standard deviation in parentheses.

\begin{tabular}{lll}
\hline Composite & Polymerization Time & \%DC \\
\hline Filtek Z100 & $20 \mathrm{~s}$ & $62.9(0.7)^{\mathrm{A}}$ \\
\hline Filtek Z100 & $40 \mathrm{~s}$ & $68.5(0.7)^{\mathrm{C}}$ \\
\hline Filtek Z250 & $20 \mathrm{~s}$ & $60.1(0.8)^{\mathrm{A}, \mathrm{F}}$ \\
\hline Filtek Z250 & $40 \mathrm{~s}$ & $57.2(0.8)^{\mathrm{B}, \mathrm{F}, \mathrm{G}}$ \\
\hline Filtek Z350XT & $20 \mathrm{~s}$ & $60.7(0.9)^{\mathrm{A}, G}$ \\
\hline Filtek Z350XT & $40 \mathrm{~s}$ & $59.2(0.9)^{\mathrm{A}, \mathrm{G}}$ \\
\hline Filtek P90 & $20 \mathrm{~s}$ & $81.7(1.1)^{\mathrm{D}}$ \\
\hline Filtek P90 & $40 \mathrm{~s}$ & $87.0(1.1)^{\mathrm{E}}$ \\
\hline
\end{tabular}

Values followed by the same superscript are not statistically different, $p>0.05$.

\section{Discussion}

The present study investigated the cytotoxicity and the degree of conversion of currently used resin composites.

One major interest factor when making a clinical decision about resin composites is based on their potential for adverse biological effects. The cytotoxicity of the resin composites has been mainly attributed to the release of monomers such as UDMA, HEMA and TEGMA, which are frequently added to the chemical composition of resins ${ }^{15}$. 
Both the resin content and percentage of monomer conversion of dental materials were considered as potential causes of cytotoxicity ${ }^{11}$. These unconverted monomers, such as TEGMA and UDMA, and photo-initiators, such as camphoroquinone, are known to be cytotoxic for cells ${ }^{16}$.

The MTT results showed that only the resin Filtek Z100 was cytotoxic. Considering the degree of conversion of the resin Filtek Z100, it wouldn't be expected to present high cytotoxicity. By presenting a lower account of the residual monomers, a smaller release of dimethacrylates into the storage medium should be expected. By comparing it with Filtek Z250, which presents more components and organic solvents (Table 1), the latter would present higher cytotoxicity.

The literature has shown that the monomer Bis-GMA, is known as the most cytotoxic one among all other monomers ${ }^{6,16}$. It should, however, discuss the characteristics of the polymer chains formed. While some composites have in their composition different amounts of components, possibly generated by chain reactions, they are shown to be more stable and, therefore, release a smaller number of monomers into the environment. Despite the cytotoxicity presented by Bis-GMA, they are important in maximizing the conversion of the monomer into methacrylate groups ${ }^{17}$. The Filtek Z100 resin, composed of Bis-GMA and TEGDMA chains, was the methacrylate resin that showed the highest degree of conversion when polymerized for 40 seconds.

A previous study by Ferracane and Condon ${ }^{18}$ reported that the majority of toxic effects from resin composites occur during the first 24 hours. Unlike these authors ${ }^{18}$, the present study showed that the release of the unreacted toxic components from the composite materials probably continues.

The formulation of dental materials affects the substances that are released and thus their cytotoxicity. Because of the severe cytotoxicity of traditional methacrylates, manufacturers have developed new materials and filling strategies. In the present study, the silorane base composite Filtek P90 showed no cytotoxic effect ${ }^{6}$.

Regarding the degree of conversion, the composite with the highest value was Filtek P90. According to Palin et al. ${ }^{19}$ the polymerisation of silorane-based composites generates reactive species with higher mobility than the free radicals generated in the polymerisation of the composite methacrylate, and this is responsible for the highest degree of conversion.

By containing higher amounts of the organic matrix, it was expected that Filtek Z250 had a higher degree of conversion compared to the other composites (Table 1 and 2). However, it did not show that. It should, however, be considered that the concentration of the materials and its chemistry has a strong influence on the characteristics of the polymerisation ${ }^{18}$.

The monomer UDMA, presented in the Z250 and Z350XT resins, has a long linear chain, without aromatic rings, which gives greater flexibility and hence also a higher degree of monomer conversion ${ }^{20,21}$ that contradict our findings.

The particle size was also related to the degree of conversion of methacrylate resins. Resins with larger particles would hinder the passage of light, increasing dispersion and reducing the conversion of the monomer ${ }^{22}$. Therefore, it was expected that 
Filtek Z100 and Z250 resins had a lower degree of polymerization compared to Filtek Z350XT. However, the results were similar. A possible explanation would be the presence of Bis-GMA in the methacrylate resins evaluated, which have a high refractive index, or due to the significant reduction of TEGDMA in Filtek Z350XT, which is related to a lower degree of conversion ${ }^{23}$.

The composites Filtek Z250 and Filtek Z350XT showed no differences when they were polymerised for 20 or 40 seconds. These findings confirm the information provided by the manufacturer that 20 seconds was enough for sufficient polymerisation of the structure of these resins when using a curing light (LED Flash lite Disculs). According to Calheiros et al. ${ }^{24}$ by increasing the time of light exposure, one does not increase the degree of conversion due to the fact that a saturation of the polymer chains of the composite is obtained.

We found no statistically significant correlation between cell viability and degree of conversion. Thus, the null hypothesis is accepted. However, more studies are needed to evaluate the cytotoxicity effect and the degree of conversion in other materials.

\section{Conclusions}

In conclusion, we observed that the levels of cytotoxicity of restorative resin materials should vary with the number and type of constituent components. As the density and stability of the connection polymer formed; this can influence the release of unreacted components.

\section{Conflict of Interest}

No potential conflict of interest relevant to this article was reported.

\section{References}

1. Vieira AR, Silva MB, Souza KKA, Filho AVA, Rosenblatt A, Modesto A. A Pragmatic Study Shows Failure of Dental Composite Fillings Is Genetically Determined: A Contribution to the Discussion on Dental Amalgams. Front Med (Lausanne). 2017 Nov 6;4:186. doi: 10.3389/fmed.2017.00186.

2. Santerre JP, Shajii L, Leung BW. Relation of dental composite formulations to their degradation and the release of hydrolyzed polymeric-resin-derived products. Crit Rev Oral Biol Med. 2001;12(2):136-51. doi: 10.1177/10454411010120020401.

3. Al-Boni R, Raja OM. Microleakage evaluation of silorane based composite versus methacrylate based composite. J Conserv Dent. 2010 Jul;13(3):152-5. doi: 10.4103/0972-0707.71649.

4. Jerg A, Schulz SD, Tomakidi P, Hellwig E, Polydorou O. Modulation of gingival cell response towards dental composites. Dent Mater. 2018 Mar;34(3):412-26. doi: 10.1016/j.dental.2017.11.025.

5. Franz A, König F, Lucas T, Watts DC, Schedle A. Cytotoxic effects of dental bonding substances as a function of degree of conversion. Dent Mater. 2009 Feb;25(2):232-9. doi: 10.1016/j.dental.2008.07.003.

6. Eick JD, Barragan-Adjemian C, Rosser J, Melander JR, Dusevich V, Weiler RA, Met al. Silorane resin supports proliferation, differentiation, and mineralization of MLO-A5 bone cells in vitro and bone formation in vivo. J Biomed Mater Res B Appl Biomater. 2012 Apr;100(3):850-61. doi: 10.1002/jbm.b.32649.

7. Duarte S Jr, Botta AC, Phark JH, Sadan A. Selected mechanical and physical properties and clinical application of a new low-shrinkage composite restoration. Quintessence Int. 2009 Sep;40(8):631-8. 
8. Yesilyurt C, Yoldas O, Altintas SH, Kusgoz A. Effects of food-simulating liquids on the mechanical properties of a silorane-based dental composite. Dent Mater J. 2009 May;28(3):362-7. doi: 10.4012/dmj.28.362.

9. Mousavinasab SM, Atai M, Salehi N, Salehi A. Effect of Shade and Light Curing Mode on the Degree of Conversion of Silorane-Based and Methacrylate-Based Resin Composites. J Dent Biomater. 2016 Dec;3(4):299-305.

10. Longo DL, Paula-Silva FW, Faccioli LH, Gatón-Hernández PM, Queiroz AM, Silva LA. Cytotoxicity and cytokine expression induced by silorane and methacrylate-based composite resins. J Appl Oral Sci. 2016 Jul-Aug;24(4):338-43. doi: 10.1590/1678-775720150449.

11. Małkiewicz K, Wychowański P, Olkowska-Truchanowicz J, Tykarska M, Czerwiński M, Wilczko M, et al. Uncompleted polymerization and cytotoxicity of dental restorative materials as potential health risk factors. Ann Agric Environ Med. 2017 Dec 23;24(4):618-23. doi: 10.5604/12321966.1235159.

12. Johnsen GF, Thieu MK, Hussain B, Pamuła E, Reseland JE, Lyngstadaas SP, et al. Own brand label restorative materials-A false bargain? J Dent. 2017 Jan;56:84-98. doi: 10.1016/j.jdent.2016.11.004.

13. Gonçalves F, Campos LMP, Rodrigues-Júnior EC, Costa FV, Marques PA, Francci CE, et al. A comparative study of bulk-fill composites: degree of conversion, post-gel shrinkage and cytotoxicity. Braz Oral Res. 2018 Mar 8;32:e17. doi: 10.1590/1807-3107bor-2018.vol32.0017.

14. Gontijo SML, Gomes ADM, Gala-García A, Sinisterra RD, Esperanza Cortés M. Evaluation of antimicrobial activity and cell viability of aloe vera sponges. Electron J Biotechnol. 2013;16(1):1-10. doi: 10.2225/vol16-issue1-fulltext-2.

15. Volk J, Engelmann J, Leyhausen G, Geurtsen W. Effects of three resin monomers on the cellular glutathione concentration of cultured human gingival fibroblasts. Dent Mater. 2006 Jun;22(6):499-505. doi: 10.1016/j.dental.2005.06.002.

16. Kong N, Jiang T, Zhou Z, Fu J. Cytotoxicity of polymerized resin cements on human dental pulp cells in vitro. Dent Mater. 2009 Nov;25(11):1371-5. doi: 10.1016/j.dental.2009.06.008.

17. Magne P, Malta DA, Enciso R, Monteiro-Junior S. Heat Treatment Influences Monomer Conversion and Bond Strength of Indirect Composite Resin Restorations. J Adhes Dent. 2015 Dec;17(6):559-66 doi: 10.3290/j.jad.a35258.

18. Ferracane JL, Condon JR. Rate of elution of leachable components from composite. Dent Mater. 1990 Oct;6(4):282-7. doi: 10.1016/S0109-5641(05)80012-0.

19. Palin WM, Fleming GJ, Nathwani H, Burke FJ, Randall RC. In vitro cuspal deflection and microleakage of maxillary premolars restored with novel low-shrink dental composites. Dent Mater. 2005 Apr;21(4):324-35. doi: 10.1016/j.dental.2004.05.005.

20. R Ruyter IE, Oysaed H. Composites for use in posterior teeth: composition and conversion. J Biomed Mater Res. 1987 Jan;21(1):11-23. doi: 10.1002/jbm.820210107.

21. Monte Alto RV, Guimarães JG, Poskus LT, da Silva EM. Depth of cure of dental composites submitted to different light-curing modes. J Appl Oral Sci. 2006 Apr;14(2):71-6. doi: 10.1590/s1678-77572006000200002.

22. Balbinot EDCA, Pereira MFCC, Skupien JA, Balbinot CEA, da Rocha G, Vieira S. Analysis of transmittance and degree of conversion of composite resins. Microsc Res Tech. 2019 Nov;82(11):1953-61. doi: 10.1002/jemt.23364.

23. Lin GSS, Abdul Ghani NRN, Ismail NH, Singbal KP, Yusuff NMM. Polymerization Shrinkage and Degree of Conversion of New Zirconia-Reinforced Rice Husk Nanohybrid Composite. Eur J Dent. 2020 Jul;14(3):448-55. doi: 10.1055/s-0040-1713951.

24. Calheiros FC, Braga RR, Kawano Y, Ballester RY. Relationship between contraction stress and degree of conversion in restorative composites. Dent Mater. 2004 Dec;20(10):939-46. doi: 10.1016/j.dental.2004.03.003. 